\title{
Prevalence and factors associated with metabolic syndrome in 6-10-year-old children
}

\author{
Alynne Christian Ribeiro Andaki ${ }^{1}$, Edmar Lacerda Mendes ${ }^{1}$, Ciro Jose Brito ${ }^{2}$, Paulo Roberto dos Santos Amorim ${ }^{3}$, \\ Rachel Wood ${ }^{4}$, Adelson Luiz Araújo Tinoco ${ }^{5}$ \\ ${ }^{1}$ Universidade Federal do Triângulo Mineiro, UFTM, Department of Sport Sciences, Uberaba, MG, Brazil; \\ ${ }^{2}$ Universidade Federal de Juiz de Fora, UFJF, Department of Physical Education, Juiz de Fora, MG, Brazil \\ ${ }^{3}$ Universidade Federal de Viçosa, UFV, Department of Physical Education, Viçosa, MG, Brazil; \\ ${ }^{4}$ Bond University, Faculty of Health Sciences and Medicine, Bond Institute of Health and Sport, Australia; \\ ${ }^{5}$ Universidade Federal de Viçosa, UFV, Department of Nutrition and Health, Viçosa, MG, Brazil
}

\begin{abstract}
Aims: to identify the prevalence of metabolic syndrome (MetS) and associated risk factors in children. Methods: a total of 1,480 Brazilian children aged 6-10 years old (52.2\% girls) participated in this populationbased, epidemiological cross-sectional study. The inclusion criteria were children born between the years 2001 and 2006, of both sexes, who did not use remedy, were not on a calorie restriction diet, and who respected the 12-hour fast for blood collection. Anthropometric measurements, blood pressure, blood collection, and completion of the Previous Day Food Questionnaire and interview using a Physical Activity List were held at school. Parents were asked to complete a questionnaire on socioeconomic status and lifestyle habits of their child. Chi-square test compared proportions and factors associated with MetS were identified using Poisson Regression. Results: Girls had significantly higher MetS prevalence compared with boys $(12.6 \%$ vs. $8.5 \%, p=0.046)$. After multivariable analysis, body fat percentage $(p=0.001)$, fat mass $(p<0.001)$, lean body mass $(\mathrm{p}<0.001)$ and sedentary behavior $(p=0.050)$ were positively associated with MetS. Conclusions: Modifiable factors such as body fat percentage, fat mass, lean body mass and sedentary behavior were associated with MetS in children. Thus, interventions targeted for weight management, and adopting healthy habits such as reducing time in front of TV/computer/video game need to be part of the lifestyle of children.
\end{abstract}

Keywords: cardiovascular risk factor, poison regression, anthropometry.

\section{Introduction}

The diagnosis and treatment of metabolic syndrome (MetS) has increasingly taken the attention of researchers and health workers, as its prevalence in children and adolescents has increased in recent years, especially among children who are obese ${ }^{1}$. For example, Ferreira et al. ${ }^{2}$ reported a MetS prevalence of $23.6 \%$ in obese Brazilian children, and a study in Guatemalan children reported that all children who had MetS were obese $(16.2 \%)^{3}$. However, MetS has also been observed in lean individuals, suggesting that obesity is a marker of the syndrome, but not the cause ${ }^{4}$. There is not a consensus about diagnostic criteria for MetS in children, but the presence of cluster metabolic disorders in children and the associated health problems is clear ${ }^{5}$.

While genetics may influence the risk of developing $\mathrm{MetS}^{6}$, environmental factors such as smoking, intake of high calorie food (fat and carbohydrates), and physical inactivity (less than 60 minutes of moderate and vigorous physical activity per day) also have a role 7,8 . Physical activity was inversely associated with the cardiovascular diseases (CVD) risk factors and sedentary behavior was directly related to the risk in 6-8-year-old children'. Excessive time in front of television, computer, video game has been found to have independent and deleterious associations with markers of adiposity and CVD risk factors ${ }^{10}$. On the other hand, there is a need to develop a better understanding of the factors associated with MetS in children, with the aim of then modifying them through behaviors that encourage the adoption of healthy lifestyle (appropriate dietary intake and increase in daily energy expenditure through physical activity) ${ }^{1}$.

There is limited literature about factors associated with MetS in children under 10 years old ${ }^{3}, 11$. In Brazil, a developing country, Borges Pretto, Correa Kaufmann, Ferreira Dutra, Pinto Albernaz ${ }^{11}$ found a high waist circumference values and family history (especially hypertension) were associated with high prevalence of CVD risk factors for MetS. Knowledge regarding the factors associated with MetS during childhood should facilitate to identification, treatment and avoidance of future complications in adulthood. As such, the aim of this study was to identify the prevalence of MetS and associated risk factors in children aged 6-10-year-old in Uberaba, Brazil. 


\section{Methods}

\section{Study design and participants}

This was a population-based, cross-sectional study using probability sampling of children 6-10 years old, from public and private elementary schools in the urban and rural areas of the municipality of Uberaba (Brazil). The required sample size was estimated based on: the number of children enrolled in primary education $(37,371)$, prevalence of $50 \%$ MetS (unknown prevalence in the municipality), tolerable error of $3.5 \%$ and a confidence level of $95 \%$. The minimum sample size of 768 children was increased by $10 \%$ to compensate for those who decline to participate and attrition, and a further $20 \%$ to minimize confounders, resulting in a final sample size estimate of 1,014 children. For sample selection, schools were stratified according to the school segment (municipal, state and private). In the first stage, 15 eligible schools were randomly selected. In the second stage, the number of children in each school segment was determined in proportion to the number of enrollments to maintain similar proportions.

After approval by the Ethics Committee on Human Beings of the Federal University of Viçosa (Of.095/2011/Comitê de Ética), the children who met the inclusion criteria (children born between the years 2001 and 2006, of both sexes, who did not use remedy, were not on a calorie restriction diet, and who respected the 12-hour fast for blood collection) and were interested in participating in the study received the Statement of Informed Consent for acknowledgement and signature of their parents. Data collection was performed on August-2011 until August-2012.

\section{Measures}

Body mass (BM), height $(\mathrm{H})$ and sitting height $(\mathrm{SH})$ were obtained in accordance with standard techniques. Body mass index (BMI) was calculated by using the formula BMI = BM $(\mathrm{kg}) / \mathrm{H}^{2}\left(\mathrm{~m}^{2}\right)$. The classification of children with overweight and obesity was conducted from the BMI/age and sex, according to the criteria of Cole, Bellizzi, Flegal, Dietz ${ }^{12}$.

Waist circumference (WC) was obtained with a flexible and inelastic tape on the midpoint between the iliac crest and the last floating rib. All measurements were made in triplicate and the average values was considered.

Four skinfold thickness (SF) were measured [triceps (TrSF), biceps (BiSF), subscapular (SbSF) and suprailiac (SiSF)] using a skinfold caliper. The measurements were performed in triplicate.

\section{Body Composition}

To calculate the body fat percentage (BF\%) equations proposed by Slaughter et $\mathrm{al}^{13}$ based on ethnicity and summation of TrSF and SbSF thickness were used. The lean body mass (LBM) was obtained by subtracting the calculated fat mass (FM) from the measured total BM. Based on $\mathrm{BF} \%$, the sample was classified according to the categories of body fatness proposed by Lohman ${ }^{14}$.

\section{Maturity offset}

Maturity Offset (MO) has been used for predict maturational state. The method includes decimal age, $\mathrm{H}, \mathrm{BM}, \mathrm{BM} / \mathrm{H}^{*} 100$ ratio, $\mathrm{SH}$ and length of lower limbs (LLL). The LLL was calculated as the difference between $\mathrm{H}$ and $\mathrm{SH}$. MO provides an estimate of the distance in years from the peak growing velocity (PGV). The MO will be negative if the child has not yet reached PGV and positive if the child has exceeded the $\mathrm{PGV}^{15}$.

\section{Blood Pressure}

Blood pressure was measured using a mercury column sphygmomanometer cuff size following standards proposed by the VI Brazilian Guidelines on Hypertension ${ }^{16}$. The classification of blood pressure was determined based on the specific cutoff points for children with appropriate according to the percentile for height and sex. Children who had systolic or diastolic blood pressure above the 90th percentile on three separate occasions were diagnosed with high blood pressure.

\section{Physical Activity}

A semi-structured questionnaire, Brazilian version of the Physical Activity Checklist Interview, was used to estimate habitual physical activity ${ }^{17}$. The cutoff point adopted to classify children who met the recommendation for MVPA was $\geq 60 \mathrm{~min}$.

\section{Lifestyle habits}

Parents were asked to complete one questionnaire containing 19 closed questions providing details about their child's lifestyle habits. The screen time was estimated from the average time spent on the computer, video game and television during the week and on weekends and sedentary behavior was defined by screen time $\geq 2 \mathrm{~h}$ per day.

\section{Socioeconomic Status}

Purchasing power of households and the education level of the household head were used to determine socioeconomic status $(\mathrm{SES})^{18}$. Families were classified as: Class A1 (higher economic class), Class A2, Class B1, Class B2, Class C1, Class C2, Class $\mathrm{D}$, Class $\mathrm{E}$ (lower economic class). 


\section{Eating Habits}

Dietary habits were assessed by the Previous Day Food Questionnaire (PDFQ-3), which is an illustrated instrument that has been validated to identify eating habits of children from 6-11 years old. The data were classified based on recommendations (number of portion per day) of the Food Guide for the Brazilian Population: promoting healthy eating ${ }^{19}$ and Ten Steps for a Healthy Diet of Children over 2 years old ${ }^{20}$.

\section{Biochemical Evaluation}

Fasting blood was collected into two BD Vacutainer tubes containing: 1) clot activator and gel separator and;2) sodium fluorite and sodium EDTA. Sample was immediately centrifuged at $3400 \mathrm{rpm}$ for eight minutes to separate serum and plasma from other blood components. Serum samples were analyzed for the determination of HDL-c and triglycerides and plasma for blood glucose levels.

\section{Metabolic Syndrome}

MetS risk was determined by the presence of at least three of the following criteria: fasting triglycerides $\geq 100 \mathrm{mg} / \mathrm{dL}$; HDL-c $<50 \mathrm{mg} / \mathrm{dL}$; fasting glucose $\geq 110 \mathrm{mg} / \mathrm{dL}$; WC $\geq 75$ th percentile for age and sex; blood pressure (diastolic or systolic) $>90$ th percentile adjusted for age, height and $\operatorname{sex}^{21}$.

\section{Statistical analysis}

Variables were tested for normality by the KolmogorovSmirnov test, and parametric and/or non-parametric tests were applied according to their distributions. Chi-square test compared proportions. Factors associated with MetS were identified using Poisson Regression. The prevalence ratio (PR) was used as a measure of association, and the Wald test was used to determine statistical significance. The dependent variable was MetS and independent were: sex, age, type of school, skinfolds thickness, body composition, maturity offset, hours of sleep per night, sedentary behavior, attends sports school, commuting to school, recommendation for moderate to vigorous intensity physical activity/MVPA and eating habits. In order to perform an adjusted analysis, we adopted the backward stepwise input method and a hierarchized conceptual model (to determine the variables input order) with three levels: 1) socio-demographic (sex, age, type of school); 2) health aspects (skinfolds thickness, body composition, maturity offset); 3 ) behavioral aspects (hours of sleep per night, sedentary behavior, attends sports school, commuting to school, recommendation for moderate to vigorous intensity physical activity/MVPA and eating habits). Variables with values of $\mathrm{p} \leq 0.20$ in the bivariate analysis were included and tested in hierarchized model. In this analysis, the variables with $\mathrm{p} \leq 0.05$ were considered significantly associated with MetS. Statistical analyses were performed with IBM SPSS 24.0 (Chicago, IL, USA) for Windows.

\section{Results}

The study included 1,480 children of both sexes $(52.2 \%$ female), median age of $8.55 \pm 1.53$ years, the majority belonging to families of economic class C $(66 \%)$, with family income between US\$ 290.00 and US\$ 478.00 (US\$1 dollar: R $\$ 3.5$ real) and the head of family had complete high school education (25.1\%).

The prevalence of hypertriglyceridemia, low HDL-c and MetS was statistically higher for girls compared to boys ( $p<$ 0.05 ), Table 1 . In this sample, $27.0 \%$ of children did not show any alterations in MetS components, whereas $43.6 \%, 18.5 \%$, $8.3 \%$ and $2.4 \%$ showed alterations in one, two, three and four components of MetS, respectively.

Table 1. Proportion of boys and girls meeting each of the criteria for metabolic syndrome

\begin{tabular}{lccccccc}
\hline \multirow{2}{*}{ MetS components } & \multicolumn{3}{c}{ Girls } & \multicolumn{5}{c}{ Boys } & p-value \\
\cline { 2 - 7 } & total & $\mathbf{n}$ & $\mathbf{\%}$ & total & $\mathbf{n}$ & $\%$ & \\
\hline Hyperglycemia & 559 & 6 & 1.1 & 493 & 5 & 1.0 & 0.900 \\
Hypertriglyceridemia & 551 & 99 & 18.0 & 494 & 60 & 12.1 & $0.009^{*}$ \\
Low HDL-c & 550 & 350 & 63.6 & 487 & 286 & 58.7 & $0.040^{*}$ \\
WC > 75th & 775 & 214 & 27.7 & 705 & 193 & 27.5 & 0.900 \\
High blood pressure & 731 & 88 & 12.0 & 672 & 71 & 10.6 & 0.380 \\
MetS & 494 & 62 & 12.6 & 435 & 37 & 8.5 & $0.046^{*}$ \\
\hline
\end{tabular}

MetS = metabolic syndrome; $\mathrm{WC} 1$ = waist circumference;

*Significant difference Chi-square test.

Figure 1 shows a linear relationship $(p<0.05)$ between prevalence of MetS across BMI categories for each sex. The prevalence of MetS was particularly high (70.8\%) among obese girls.

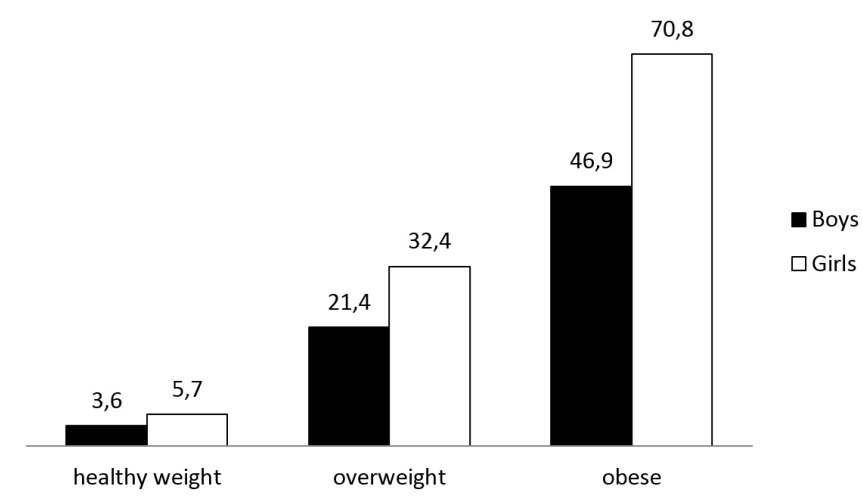

Figure 1. Prevalence of metabolic syndrome by sex and body mass index in children aged 6-10 years old. 
Figure 1 shows a linear relationship $(\mathrm{p}<0.05)$ between prevalence of MetS across BMI categories for each sex. The prevalence of MetS was particularly high (70.8\%) among obese girls

After multivariable analysis BF\%, FM, LBM and sedentary behavior were positively associated with MetS ( $\leq 0.05$; Table 2$)$.

Table 2. Factors Associated with Metabolic Syndrome in children aged 6-10 years old

\begin{tabular}{|c|c|c|c|c|}
\hline \multirow{2}{*}{ Variables } & \multicolumn{2}{|c|}{ Bivariate Analysis } & \multicolumn{2}{|c|}{ Multivariable Analysis } \\
\hline & PR (CI 95\%) & $p$-value & PR (CI 95\%) & $p$-value \\
\hline \multicolumn{5}{|l|}{$\begin{array}{l}\text { Block 1: Sociodemographic } \\
\text { Aspects }\end{array}$} \\
\hline \multicolumn{5}{|l|}{ Sex } \\
\hline Boys & 1 & 0.040 & 1 & 0.259 \\
\hline Girls & $1.47(1.003,2.171)$ & & $1.45(0.760,2.776)$ & \\
\hline \multicolumn{5}{|l|}{ Age } \\
\hline 6 years & 1 & $<0.001$ & 1 & 0.314 \\
\hline 7 years & $1.17(0.521,2.631)$ & & $0.33(0.119,0.959)$ & \\
\hline 8 years & $1.48(0.685,3.207)$ & & $0.37(0.130,1.061)$ & \\
\hline 9 years & $1.91(0.912,4.014)$ & & $0.31(0.083,1.200)$ & \\
\hline 10 years & $3.20(1.636,6.625)$ & & $0.24(0.049,1.246)$ & \\
\hline \multicolumn{5}{|l|}{ Type of School } \\
\hline Public & 1 & $<0.001$ & 1 & 0.250 \\
\hline Private & $2.40(1.481,3.924)$ & & $1,47(0.762,2.838)$ & \\
\hline \multicolumn{5}{|l|}{ Block 2 - Health Aspects } \\
\hline \multicolumn{5}{|l|}{ Skinfolds } \\
\hline Biceps (mm/dm3) & $1.16(1.144,1.194)$ & $<0.001$ & $1.00(0.926,1.084)$ & 0.969 \\
\hline Triceps (mm/dm3) & $1.16(1.139,1.183)$ & $<0.001$ & $0.91(0.794,1.052)$ & 0.210 \\
\hline Subscapular (mm/dm3) & $1.10(1.089,1.116)$ & $<0.001$ & $1.02(0.912,1.145)$ & 0.710 \\
\hline Suprailiac (mm/dm3) & $1.08(1.071,1.093)$ & $<0.001$ & $0.99(0.955,1.038)$ & 0.832 \\
\hline \multicolumn{5}{|l|}{$\begin{array}{l}\text { Body } \\
\text { Composition }\end{array}$} \\
\hline$\%$ Body Fat & $1.09(1.081,1.105)$ & $<0.001$ & $1.50(1.218,1.850)$ & 0.001 \\
\hline Lean Body Mass (Kg) & $1.18(1.152,1.224)$ & $<0.001$ & $1.25(1.106,1.432)$ & $<0.001$ \\
\hline Fat Mass (Kg) & $1.11(1.093,1.130)$ & $<0.001$ & $0.53(0.417,0.693)$ & $<0.001$ \\
\hline Maturity offset (years) & $2.28(1.952,2.663)$ & $<0.001$ & $1.33(0.541,3.307)$ & 0.528 \\
\hline \multicolumn{5}{|c|}{ Block 3 - Behavioral Aspects } \\
\hline \multicolumn{5}{|l|}{ Hours of sleep per night } \\
\hline$\geq 8$ hours & 1 & 0.350 & & \\
\hline$>4$ and $<8$ hours & $1.23(0.791,1.935)$ & & & \\
\hline \multicolumn{5}{|l|}{ Sedentary behavior } \\
\hline$<2$ hours of screen time & 1 & & 1 & 0.050 \\
\hline$\geq 2$ hours of screen time & $1.39(0.910,2.141)$ & 0.12 & $0.61(0.377,1.000)$ & \\
\hline \multicolumn{5}{|l|}{ Attends Sports School } \\
\hline Yes & 1 & 0.920 & & \\
\hline No & $1.02(0.562,1.884)$ & & & \\
\hline \multicolumn{5}{|l|}{ Commuting to school } \\
\hline Active & 1 & 0.300 & & \\
\hline
\end{tabular}




\begin{tabular}{|c|c|c|c|c|}
\hline Passive & $1.253(0.814,1.928)$ & & & \\
\hline \multicolumn{5}{|l|}{ Recommendation for MVPA } \\
\hline $\mathrm{MVPA} \geq 60 \mathrm{~min}$ & 1 & 0.730 & & \\
\hline $\mathrm{MVPA}<60 \mathrm{~min}$ & $1.08(0.696,1.677)$ & & & \\
\hline \multicolumn{5}{|c|}{$\begin{array}{l}\text { Recommendation for vegeta- } \\
\text { bles/legumes }\end{array}$} \\
\hline Yes ( $\geq 5$ serving per day) & 1 & 0.970 & & \\
\hline No & $1.03(0.161,6.652)$ & & & \\
\hline \multicolumn{5}{|l|}{ Recommendation for fruits } \\
\hline Yes ( $\geq 3$ serving per day) & 1 & 0.300 & & \\
\hline No & $1.32(0.778,2.239)$ & & & \\
\hline \multicolumn{5}{|l|}{ Recommendation for candy } \\
\hline Yes ( $\leq 1$ serving per day) & 1 & 0.060 & & \\
\hline No & $2.15(0.958,4.837)$ & & & \\
\hline \multicolumn{5}{|l|}{$\begin{array}{l}\text { Recommendation for fatty } \\
\text { food }\end{array}$} \\
\hline Yes ( $\leq 1$ serving per day) & 1 & 0.020 & 1 & 0.211 \\
\hline No & $2.42(1.099,5.348)$ & & $0.56(0.235,1.377)$ & \\
\hline \multicolumn{5}{|l|}{ Recommendation for Soda } \\
\hline 0 portions per day & 1 & 0.250 & & \\
\hline 1 to 2 portions per day & $1.460(0.915,2.330)$ & & & \\
\hline$>3$ portions per day & $1.076(0.461,2.515)$ & & & \\
\hline
\end{tabular}

$\mathrm{PR}=$ prevalence ratio $\mathrm{CI}=$ confidence interval $\mathrm{MVPA}=$ moderate and vigorous physical activity .

In the pre and post intervention intragroup, it was found that in males, there was a reduction of CPT/VG time on weekdays by about $14.0 \%$. This association was considered weak in terms of effect size. In females, there was a decline of $8.9 \%$ in TV time on weekdays. There was no change from baseline to postintervention in the CG. For the other electronics, there was no significant reduction in screen time in both IG and CG (Table 2).

Logistic regression was used to test the reduction of the proportion of adolescents exposed to excess screen time in IG compared to CG. Analyses were adjusted for economic level, age and screen time at baseline. There were no significant results in the odds ratio of reducing the proportion of adolescents' excess screen time, when comparing the IG with the GC (Table 3).

\section{Discussion}

The main finding of this study was association between MetS and modifiable factors such as BF\%, FM, LBM and sedentary behavior. This study showed an association (linear trend) between MetS prevalence and BMI categories (Fig.1). MetS was 13 times more prevalent in children who are obese compared with healthy weight (Table 2). All studies using modifications of the National Cholesterol Education Programs - Adult Treatment Panel III (NCEP-ATPIII) criteria to define MetS reported prevalence of MetS in obese children (11.3 \pm 2.4 years) of $45.0 \%$ in Chile ${ }^{22}, 23.6 \%$ in $7-11$-year-old Brazilian children ${ }^{2}$, and $30.7 \%$ in 8 -18-year-old children in India ${ }^{23}$. Another study found the prevalence of $34.5 \%, 10.7 \%$ and $0.3 \%$ MetS in obese, overweight and weight healthy in 6-16-year-old Brazilian children, respectively ${ }^{24}$. However, the cutoff points as well as the MetS components used must be taken into account when interpreting these results, because there is no consensus among the criteria adopted. It is important to note that regardless criterion used the prevalence has been shown alarming in obese children.

Our results showed a higher MetS prevalence among children enrolled in private schools compared to those enrolled in public schools (Table 2, bivariate model). This is in contrast with other studies that have reported no difference in MetS prevalence among children and adolescents enrolled in public and private schools in Brazil ${ }^{25}$ and Argentina ${ }^{26}$. While children who attend private schools have higher SES than public schoolchildren in $\mathrm{Brazil}^{24}$ reported a higher proportion of children with MetS among those with higher SES (OR = 4.7 \% vs. $2.7 \%$ ), it used the same criterion as the present study. Canadian children and adolescents from households with the highest income and educational attainment levels showed the lowest prevalence of one or more MetS risk factors ${ }^{27}$. Furthermore, it was shown that lower parent education level increases the chances of MetS in girls $(\mathrm{OR}=1.2)$ and boys $(\mathrm{OR}=1.3)^{1}$. Low maternal schooling was the most important factor associated with high CVD risk 
factors in 7-10-year-old Brazilian children (OR=7.36, IC95\%: $2.09 ; 25.97)^{28}$. Conflicting results on the association between sociodemographic variables were observed among studies that involve children in different contexts. Data available in Brazil, Seki, Matsuo, Carrilho ${ }^{24}$ suggest that MetS occurs most frequently among children with higher SES, possibly through access to new technologies increasing screen time, minimizing displacement by parental car use, reducing habitual physical activity and increasing consumption of energy-dense foods. It is noteworthy that in Uberaba there is a program for monitoring of school meals offered to children in municipality schools. In addition, Minas Gerais (district) has a legislation that regulates the sale of meals in public/private schools; specifically, it prohibits the sale of fatty foods produced with saturated and trans fat. This type of intervention/policies could be effective strategies to minimize the MetS prevalence in public and private schools.

It is recommended that children increase their physical activity level and reduce time in sedentary behavior in order to obtain health benefits. Sedentary behavior, which was defined in the present study as $\geq 2 \mathrm{~h}$ /day of screen time, was estimated as the time that children spend in front of the screen (TV + $\mathrm{PC}+$ game), and it was associated with MetS. In a study in Korean children and adolescents, those in the top quartile ( $\geq 35 \mathrm{~h} /$ week or $\sim 5 \mathrm{~h} /$ day) for screen time (TV $+\mathrm{PC}$ ) had a 2.23 time greater risk of being diagnosed with MetS than those located in the bottom quartile $(\leq 16 \mathrm{~h} /$ week or $\sim 2.2 \mathrm{~h} /$ day), even after adjustment for age, family income and area of residence ${ }^{7}$. This result suggests that sedentary behavior is associated with increased MetS risk and it was directly related with cardiometabolic risk in Finnish children?.

The BF\% and FM (kg) were confirmed to be important factors associated with MetS. Girls showed significantly higher values of $\mathrm{BF} \%$ and $\mathrm{FM}$ than boys (data not reported), as well as higher values of MetS prevalence. It is known that the high $\mathrm{BF} \%$, therefore greater accumulation of body fat mass, is directly associated with the formation of atheroma plaque, the occurrence of type-2 diabetes and insulin resistance ${ }^{29}$.

Among dietary recommendations tested, only exceeding the fatty food recommendation was associated with MetS in bivariate model. Kelidash et all reported that the risk of developing MetS in Iranian children and adolescents increases with consumption of hydrogenated saturated fat (boys $\mathrm{OR}=1.3$; girls $\mathrm{OR}=1.3$ ). They also reported that the consumption of sweets and candies increased the MetS risk in both sexes, and the consumption of fruits and vegetables was considered protective MetS risk factor. In this study, there was no association between MetS and recommended intake of candy, nor fruits and vegetables, however, the Brazilian Guideline on Diagnosis and Treatment of Metabolic Syndrome suggests as a primary prevention, the reduction of calories intake in the fat form, changing consumption of saturated fats to unsaturated fats and reducing the consumption of trans fats (hydrogenated) ${ }^{30}$. There is a need for greater encouragement of healthy food starting in childhood, and parent's participation is crucial in this task.
These results show the need to implement healthy habits in public and main private schools in Uberaba, Brazil as well as improve quality of the diet, especially the reduction in fatty food intake and sedentary behavior. Girls and children who are obese have higher MetS prevalence than others, and thus special attention should be paid to this population.

Some limitations were present in this study, such as absence of direct measures to physical activity and sedentary behavior, these variables were assessed by questionnaire. An indirect measure that may overestimate the habitual physical activity, in addition to the difficulty of the characteristic recording of children, can cause bias in the results. The data collection happened in different schools and different time of the year. The variations in period maybe influence on practice of physical activity and sedentary behavior because of different seasons of the years. The MetS criterion chosen makes it difficult to compare it with other criteria in the literature, because this cuttof point were adapted and dichotomizing continuous data clearly result in reduced sensitivity. It is noteworthy the use of a representative population children under 10-year-old, and the number of independent variables tested were the strongest points of this study.

\section{Conclusion}

Modifiable factors such as body fat percentage, fat mass, lean body mass and sedentary behavior were associated with MetS in children. Thus, interventions targeted for weight management, and adopting healthy habits such as reducing time in front of TV/computer/video game need to be part of the lifestyle of children.

\section{Acknowledgments}

This study was funded by Fundação de Amparo a Pesquisa de Minas Gerais/FAPEMIG (Minas Gerais State Research Foundation - CDS - APQ-02279-11).

\section{References}

1. Kelishadi R, Gouya MM, Adeli K, Ardalan G, Gheiratmand R, Majdzadeh R, et al. Factors associated with the metabolic syndrome in a national sample of youths: CASPIAN Study. Nutr Metab Cardiovasc Dis. 2008;18(7):461-70.

2. Ferreira AP, Ferreira CB, Brito CJ, Pitanga FJ, Moraes CF, Naves LA, et al. Prediction of metabolic syndrome in children through anthropometric indicators. Arq Bras Cardiol. 2011;96(2):121-5.

3. Mbowe O, Diaz A, Wallace J, Mazariegos M, Jolly P. Prevalence of metabolic syndrome and associated cardiovascular risk factors in Guatemalan school children. Matern Child Health J. 2014;18(7):1619-27. 
4. Freedland ES. Role of a critical visceral adipose tissue threshold (CVATT) in metabolic syndrome: implications for controlling dietary carbohydrates: a review. Nutr Metab (Lond). 2004;1(1):12.

5. Damiani D, Kuba VM, Cominato L, Dichtchekenian V, Menezes Filho HC. [Metabolic syndrome in children and adolescents: doubts about terminology but not about cardiometabolic risks]. Arq Bras Endocrinol Metabol. 2011;55(8):576-82.

6. Butte NF, Comuzzie AG, Cole SA, Mehta NR, Cai G, Tejero M, et al. Quantitative genetic analysis of the metabolic syndrome in Hispanic children. Pediatr Res. 2005;58(6):1243-8.

7. Kang HT, Lee HR, Shim JY, Shin YH, Park BJ, Lee YJ. Association between screen time and metabolic syndrome in children and adolescents in Korea: the 2005 Korean National Health and Nutrition Examination Survey. Diabetes Res Clin Pract. 2010;89(1):72-8.

8. Steinberger J, Daniels SR, Eckel RH, Hayman L, Lustig RH, McCrindle B, et al. Progress and challenges in metabolic syndrome in children and adolescents: a scientific statement from the American Heart Association Atherosclerosis, Hypertension, and Obesity in the Young Committee of the Council on Cardiovascular Disease in the Young; Council on Cardiovascular Nursing; and Council on Nutrition, Physical Activity, and Metabolism. Circulation. 2009;119(4):628-47.

9. Vaisto J, Eloranta AM, Viitasalo A, Tompuri T, Lintu N, Karjalainen $\mathrm{P}$, et al. Physical activity and sedentary behaviour in relation to cardiometabolic risk in children: cross-sectional findings from the Physical Activity and Nutrition in Children (PANIC) Study. Int J Behav Nutr Phys Act. 2014;11:55.

10. Saunders TJ, Chaput JP, Tremblay MS. Sedentary behaviour as an emerging risk factor for cardiometabolic diseases in children and youth. Can J Diabetes. 2014;38(1):53-61.

11. Borges Pretto AD, Correa Kaufmann C, Ferreira Dutra G, Pinto Albernaz E. Prevalence of Factors Associated to Metabolic Syndrome in a Cohort of Children in South Brazil. Nutr Hosp. 2015;32(1):118-23.

12. Cole TJ, Bellizzi MC, Flegal KM, Dietz WH. Establishing a standard definition for child overweight and obesity worldwide: international survey. BMJ. 2000;320(7244):1240-3.

13. Slaughter MH, Lohman TG, Boileau RA, Horswill CA, Stillman RJ, Van Loan MD, et al. Skinfold equations for estimation of body fatness in children and youth. Hum Biol. 1988;60(5):709-23.

14. Lohman TG. The Use of Skinfold to Estimate Body Fatness on Children and Youth. Journal of Physical Education, Recreation \& Dance. 1987;58(9):98-103.

15. Mirwald RL, Baxter-Jones AD, Bailey DA, Beunen GP. An assessment of maturity from anthropometric measurements. Med Sci Sports Exerc. 2002;34(4):689-94.

16. VI Brazilian Guidelines on Hypertension. Arq Bras Cardiol. 2010;95(1 Suppl):1-51.
17. Adami F, Cruciani F, Douek M, Sewell CD, Mariath AB, Hinnig Pde F, et al. Reliability of the Brazilian version of the Physical Activity Checklist Interview in children. Rev Saude Publica. 2011;45(2):321-33.

18. Associação Brasileira de Empresas de Pesquisa. Critério de Classificação econômica 2011 [Available from: http://www. abep.org/criterio-brasil.

19. Brasil, Ministério da Saúde, Secretaria de Atenção à Saúde. Guia alimentar para a população brasileira: promovendo a alimentação saudável. Brasília: Ministério da Saúde; 2008. $210 \mathrm{p}$.

20. Brasil, Ministério da Saúde, Secretaria de Atenção à Saúde, Departamento de Atenção Básica. Dez passos para uma alimentação saudável: guia alimentar para crianças menores de 2 anos: um guia para o profissional da saúde na atenção básica. Brasília: Ministério da Saúde; 2013.

21. de Ferranti SD, Gauvreau K, Ludwig DS, Neufeld EJ, Newburger JW, Rifai N. Prevalence of the metabolic syndrome in American adolescents: findings from the Third National Health and Nutrition Examination Survey. Circulation. 2004;110(16):2494-7.

22. Eyzaguirre F, Silva R, Roman R, Palacio A, Cosentino M, Vega $\mathrm{V}$, et al. [Prevalence of metabolic syndrome in children and adolescents who consult with obesity]. Rev Med Chil. 2011;139(6):732-8.

23. Andrabi SM, Bhat MH, Andrabi SR, Kamili MM, Imran A, Nisar I, et al. Prevalence of metabolic syndrome in 8-18-yearold school-going children of Srinagar city of Kashmir India. Indian J Endocrinol Metab. 2013;17(1):95-100.

24. Seki M, Matsuo T, Carrilho AJ. Prevalence of metabolic syndrome and associated risk factors in Brazilian schoolchildren. Public Health Nutr. 2009;12(7):947-52.

25. Guimaraes IC, Moura de Almeida A, Guimaraes AC. Metabolic syndrome in Brazilian adolescents: the effect of body weight. Diabetes Care. 2008;31(2):e4.

26. Gotthelf SJ. Prevalence of Metabolic Syndrome as Defined by the International Diabetes Federation (IDF) in Adolescentsfrom Salta, Argentina. Rev Fed Arg Cardiol. 2013;42(2):119-26.

27. MacPherson M, de Groh M, Loukine L, Prud'homme D, Dubois L. Prevalence of metabolic syndrome and its risk factors in Canadian children and adolescents: Canadian Health Measures Survey Cycle 1 (2007-2009) and Cycle 2 (2009-2011). Health Promot Chronic Dis Prev Can. 2016;36(2):32-40.

28. Molina Mdel C, Faria CP, Montero MP, Cade NV, Mill JG. [Cardiovascular risk factors in 7-to-10-year-old children in Vitoria, Espirito Santo State, Brazil]. Cad Saude Publica. 2010;26(5):909-17.

29. Gutin B, Islam S, Manos T, Cucuzzo N, Smith C, Stachura ME. Relation of percentage of body fat and maximal aerobic capacity to risk factors for atherosclerosis and diabetes in black and white seven- to eleven-year-old children. J Pediatr. 1994;125(6 Pt 1):847-52. 
30. I Brazilian guidelines on diagnosis and treatment of metabolic syndrome. Arq Bras Cardiol. 2005;84 Suppl $1: 1-28$.

\section{Corresponding author}

Alynne Christian Ribeiro Andaki

Institute of Health Sciences, Department of Sport Sciences, Federal University of

Triângulo Mineiro, Av. Getúlio Guaritá, nº 159 - Centro Educacional, Sala 313,

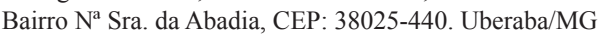

E-mail: alynneandaki@yahoo.com.br or alynne.andaki@uftm.edu.br
Manuscript received on April 9, 2018

Manuscript accepted on June 29, 2018



Motriz. The Journal of Physical Education. UNESP. Rio Claro, SP, Brazil - eISSN: 1980-6574 - under a license Creative Commons - Version 3.0 